\title{
Development of a syngas-fired catalytic combustion system for hybrid solar-thermal applications
}

\author{
Mayank Gupta, Santanu Pramanik, R V Ravikrishna*
}

\begin{abstract}
This paper describes the development and operation of a catalytic combustion system for use with syngas as an important component of a hybrid heating source for solar-thermal power generation. The reactor consists of a cylindrical ceramic monolith with porous alumina washcoat in which platinum is distributed as the catalyst. Two fuel-rich equivalence ratios were studied over a range of flow rates. The fuel-rich conditions permit low temperature combustion without the problem of hotspots likely to occur under fuel-lean conditions with hydrogen-containing fuels. Experimental data of temperature and species concentration at the exit of the reactor have been reported for a maximum fuel thermal input of $34 \mathrm{~kW}$. The system exhibited quick start-up with a light-off time of around 60 seconds and a steady-state time of around 200 seconds as determined from the transient temperature profiles. The experimental results have also been complemented with detailed twodimensional numerical simulations for improved understanding of the combustion characteristics in the reactor. The simulations suggest that the combustion system can be operated at a turn-down ratios far in excess of 1.67, which is the maximum value that has been investigated in the present setup. Stable operation, quick startup, and high turn-down ratio are some of the key features that enable the proposed combustion system to accommodate the transients in solar-thermal applications.
\end{abstract}

Keywords: solar-thermal, biomass, hybrid, catalytic combustion, syngas

\section{Introduction}

Hybridization of energy sources such as solar, wind and biomass are an effective strategy to accommodate the transients in renewable power generation [1]. Such systems are commonly referred to as Hybrid Renewable Energy Systems (HRES). The idea is to leverage the output from multiple sources against the intermittency of weather conditions. This reduces the cost of energy production and increases the reliability of the power generation system. Several hybridization schemes such as photovoltaics and wind [2, 3], wind and solar-thermal [4], solar-thermal and biomass [7-9], and a combination of these $[5,6]$ have been proposed in the literature. In spite of hybridization, systems such as wind and solar usually require a fossil fuel backup for continuous operation. A promising renewable strategy for the elimination of fossil-fuel backup is hybridization with biomass. The focus of the present work is to develop a combustion system based on biomass-derived syngas for the continuous operation of solar-thermal power generation units.

Biomass is a versatile fuel due to its availability from multiple sources and several methods of utilization. One such established method for the generation of power is gasification. Gasification is a process in which the chemical energy of the solid biomass is converted into that of a gaseous fuel known as syngas or product gas. For air-blown gasification of biomass, the typical composition of *Corresponding author, Email: ravikris@ mecheng.iisc.ernet.in 
syngas can be represented as $20 \% \mathrm{CO}, 20 \% \mathrm{H}_{2}, 2 \% \mathrm{CH}_{4}, 12 \% \mathrm{CO}_{2}$ and $46 \% \mathrm{~N}_{2}$ with a calorific value of around $5 \mathrm{MJ} / \mathrm{m}^{3}$ [7]. When compared to direct combustion of biomass, gasification offers the additional advantage of syngas storage and easy transportation from the point of production to the point of utilization. The capacity of a gasification unit is different for different types of gasifier and can vary from $1 \mathrm{MW}$ to about $300 \mathrm{MW}$ [10-12]. The efficiency of biomass to electricity conversion reported in the literature varies between 15 - 43\%, with a mean value of $27 \%$ [13]. In comparison to fossil fuels such as coal, the cost of electricity from biomass is cheaper when environmental externalities such as human health, soil erosion, etc. are taken into account [14]. The highest reported $\mathrm{CO}_{2}$ emission by a biomass electricity plant [15] is less than the lowest emitting natural gas plant by a factor of 3 and the lowest emitting coal power plant by a factor of 5 [10].

The primary considerations in the development and operation of a syngas combustion system for a solar-biomass hybrid system are the relatively lower temperature requirement, ultra-low pollutant emissions and startup time. Among these requirements, the achievement of low temperature relevant to solar-thermal technologies is particularly challenging. The maximum solar cycle temperature can be as low as $700 \mathrm{~K}$ for parabolic troughs to $1300 \mathrm{~K}$ for solar towers with central receivers $[16,17]$. This temperature range is below the flammability limit of syngas and can only be achieved in conventional gas-phase combustion systems by the staging of air. Another technology that is particularly suitable for such low-temperature applications is catalytic combustion. In catalytic combustion, the fuel is oxidized in the presence of catalysts that help to extend the flammability limit by lowering the activation energy [18]. Catalytic combustion systems have the potential for near-zero $\mathrm{NO}_{\mathrm{x}}$ emission levels and can facilitate quick startup when the inlet temperature is greater than the catalyst light-off temperature.

Catalytic combustion systems can be operated both under fuel-rich and fuel-lean conditions. For syngas and other hydrogen containing fuels, fuel-rich combustion is preferred as fuel-lean combustion can give rise to hot spots that are detrimental to the structural integrity of the catalyst substrate [20]. The excess fuel in the exhaust of a fuel-rich combustion system can be subsequently oxidized in a second-stage combustor possibly to feed other power cycles [21-23]. Thus, the motivation for the present work is to develop a catalytic combustion system for utilizing biomass-derived syngas typically associated with very low calorific value $\left(\sim 5 \mathrm{MJ} / \mathrm{m}^{3}\right)$. Fuel-rich catalytic combustion of methane and coal-derived syngas for gas turbine applications has been studied by Etemad et al. [22, 23]. Experimental and numerical studies on rich catalytic combustion of hydrogen over catalysts such as platinum and rhodium have been reported by various authors [24-26]. Rich catalytic combustion of methane (also known as catalytic partial oxidation) is of special interest in the production of syngas from hydrocarbons [27-29]. Catalytic combustion of $\mathrm{H}_{2} / \mathrm{CO}$ mixtures has been studied under fuel lean [30-31] and fuel-rich conditions [32] to understand the intrinsic chemical kinetics in such systems. However, fuel-rich catalytic combustion of biomass-derived syngas, with its particularly low calorific value, has not been reported in the literature. The present study also fills this gap in the literature. 
The present study reports experimental results for the development and operation of a $34-\mathrm{kW}$ syngas combustion system operating under conditions relevant to solar-thermal plants. This power level has been chosen to provide a hybrid heating source for a supercritical $\mathrm{CO}_{2}$ Brayton cycle loop currently being setup as part of the SERIIUS initiative [33]. The novelty in the current work concerns the application of catalytic combustion of biomass-derived syngas for the continuous generation of renewable power. Platinum has been chosen as the catalyst due to its superior activity with $\mathrm{H}_{2}$ and CO. The experimental results have been complemented with detailed numerical simulations for gaining insight into the combustion process. The next few sections describe the details of the catalytic combustor, experimental setup, results from the experimental studies, numerical model, comparison of model predictions with data, followed by a summary of the findings from the present study.

\section{Experimental work}

\subsection{Catalytic Combustor}

The catalytic combustion system comprising of the reactor and the flow lines is shown in Figure 1. The diffuser is fitted with a perforated chamber containing stainless steel spheres of 3-mm diameter. This ensured a uniform velocity profile at the entrance of the monolith that varied within $\pm 5 \%$ of the mean value. This was verified by measuring the exit velocity using a hot-wire anemometer. The perforated chamber also avoided possibility of any flashback of the flame in the premixed charge. The diffuser was followed by a flow-straightening section that consisted of a 20-mm thick cylindrical honeycomb made of Hastelloy. This was followed by the catalytic monolith, a converging section and the exhaust nozzle. The monolith was $150-\mathrm{mm}$ long and $150-\mathrm{mm}$ in diameter and consisted of square channels with a density of 400 cells per square inch. The substrate of the monolith was made of the ceramic material cordierite, while the inner walls of the channels were lined with a porous washcoat of alumina $\left(\mathrm{Al}_{2} \mathrm{O}_{3}\right)$. Platinum was distributed in this porous washcoat. Table 1 gives the detailed specifications of the catalytic monolith.

\subsection{Flow system}

The air and fuel flow into the system were controlled by mass flow controllers (make: Alicat) with a range of 0-1000 SLPM with an accuracy of $\pm 1 \%$ at the maximum flow rate. At startup, for the purpose of achieving catalyst light-off, the fuel was preheated in a $15-\mathrm{kW}$ furnace-type heater with PID temperature control. The fuel was supplied from pressurized cylinders and had a volumetric composition of $20 \% \mathrm{CO}, 12 \% \mathrm{CO}_{2}, 20 \% \mathrm{H}_{2}, 2 \% \mathrm{CH}_{4}$ and $46 \% \mathrm{~N}_{2}$. A bypass line was incorporated to preheat the catalytic combustion system using air rather than fuel prior to starting the experiments in order to avoid wastage of fuel. After reaching a steady temperature, the bypass valve was closed and fuel and air were separately introduced into the mixing chamber. The preheated fuel was mixed with the air in the mixing chamber at a particular equivalence ratio determined by the flow rates. This fuelair stream was subsequently oxidized in the catalytic monolith.

*Corresponding author, Email: ravikris@ mecheng.iisc.ernet.in 


\subsection{Instrumentation and data acquisition}

For temperature measurements, sheathed K-type (chromel-alumel) thermocouples of $1.5 \mathrm{~mm}$ diameter were used at the inlet and outlet of the catalytic monolith. The temperature was corrected for radiation losses and this correction was found to be around 30-40 K for the present work [34]. At the inlet, two thermocouples were placed (center and peripheral positions) $50-\mathrm{mm}$ below the monolith. At the outlet, a total of eight thermocouples were placed at various radial locations ( $0 \mathrm{~mm}$ to $70 \mathrm{~mm}$ ) about 50-mm above the monolith. Temperature data was acquired at a sampling frequency of $15 \mathrm{~Hz}$ using a data acquisition system (model: PXIe-4353, make: National Instruments). The species concentration data were acquired using an exhaust gas analyzer (make: MRU) that can measure CO (0-20\% by vol.), $\mathrm{CO}_{2}(0-20 \%), \mathrm{O}_{2}(0-25 \%), \mathrm{NO}_{\mathrm{x}}(0-2000 \mathrm{ppm})$ and hydrocarbons $(0-20000 \mathrm{ppm})$, with an accuracy of $\pm 5 \%$. The resolution for the measurement of $\mathrm{CO}, \mathrm{CO}_{2}, \mathrm{O}_{2}, \mathrm{NO}_{\mathrm{x}}$ and hydrocarbons are $0.01 \%, 0.1 \%, 0.01 \%, 1-\mathrm{ppm}$, and 1-ppm, respectively. The hydrocarbon measurement was calibrated for methane as chemical equilibrium analysis predicted negligible production of higher hydrocarbons $(\sim 0.1 \mathrm{ppm})$. In general, all measurements of temperature and species were repeatable within $\pm 2 \%$. The temperature of the inlet air across all the experiments varied between $\pm 7 \mathrm{~K}$.

\subsection{Determination of experimental conditions}

The experimental conditions were determined considering the maximum allowable temperature in the catalytic reactor and flashback in the premixed fuel-air mixture. For continuous operation, a maximum temperature of $1073 \mathrm{~K}$ was specified by the monolith manufacturer. The variation of adiabatic flame temperature as a function of equivalence ratio for the selected composition of biomass-derived syngas is shown in Fig. 2. The inlet temperature of $503 \mathrm{~K}$ is close to the reported light-off temperature for rich catalytic combustion of syngas [22]. The lowest equivalence ratio for the thermally safe operation was determined to be 4 . The upper equivalence ratio considered for the present study was 5. For equivalence ratio values beyond, the temperature rise would be lower than the required value; moreover, it may lead to undesirable effects such as carbon deposition on the monolith.

Initial trials revealed that the phenomenon of flashback was a serious issue at low flow rates. The flow rates were then determined using laminar flame speed calculations. The detailed $\mathrm{C}_{2} / \mathrm{H} / \mathrm{O}$ mechanism of Warnatz et al. [35] was used to determine the laminar flame speeds at equivalence ratio of $4, \mathrm{P}=1$ bar and unburned mixture temperature of $600 \mathrm{~K}$. The unburned flame speed value obtained was 16 $\mathrm{cm} / \mathrm{s}$. Considering a factor of safety of 4 , the minimum flow rate was determined to be 300 SLPM for $\Phi=4$. The large factor of safety was incorporated to account for any local non-uniformity in the flow. The upper flow rate of 500 SLPM was selected to operate the reactor at a desired power level of 34 $\mathrm{kW}$. An intermediate value of 400 SLPM has also been used in the present study. The Reynolds number in the monolith channels corresponding to the flow rates of 300, 400 and 500 SLPM was in the laminar regime, thereby justifying the use of laminar flame speed calculations. The complete set of experimental conditions is shown in Table 2.

*Corresponding author, Email: ravikris@mecheng.iisc.ernet.in 


\subsection{Experimental results}

In this section, temperature measurements under both transient and steady-state conditions are reported and discussed. Additionally, catalytic light-off timescales and species measurements at the exhaust of the monolith are also reported.

\subsubsection{Transient characteristics}

Figure 3 shows the transient temperature profiles measured at the inlet and the exit of the catalytic combustion system for different flow conditions. The point of inflection on the exit temperature curve signified the light-off condition. For all the cases, it was observed that the time required for light-off was reduced with increase in the flow rate. The transient phase occurs after the light-off phase. The duration of the transient phase was also found to significantly reduce with increase in the flow rate. However, both these parameters were observed to be fairly insensitive to the equivalence ratio (Figure 4). The dependence is found to be more on the convective transport. The light-off time obtained was 50 seconds for 500 SLPM and 65 seconds at 300 SLPM. Overall, the system had a short startup time corresponding to less than 5 minutes at the lowest flow rate. This characteristic is highly desirable to quickly respond to the transients in solar-thermal power generation.

\subsubsection{Temperature}

Figure 5 shows the measured peak outlet temperatures as a function of the flow rate. For equivalence ratios of 4 and 5, the experimentally-observed temperature rise is $516 \mathrm{~K}$ and $449 \mathrm{~K}$, respectively. It is interesting to note from Fig. 5 that there is no significant effect of flow rates on temperature rise for the range of flow rates studied. This indicates that the residence time available in the current reactor is sufficient for the completion of reactions under the given conditions.

Figure 6 shows the radial temperature profiles at the reactor outlet for equivalence ratios of 4 and 5, and a flow rate of 300 SLPM. The uncertainty in temperature measurements corresponds to a value of around $\pm 2 \%$ which translates to only around $\pm 20 \mathrm{~K}$ for the measured temperatures. The observed trend in the radial variation of temperature is indicative of the heat loss to the walls of the reactor It can be observed that the temperature variation over the central region of the monolith (radius of $30-\mathrm{mm}$ ) is around $40 \mathrm{~K}$ only. Thus, the temperature in this region is reasonably uniform. However, beyond this region and closer to the wall, there is a larger gradient, mainly driven by the heat loss to the walls. Even in this region, at a radial location of $60-\mathrm{mm}$, the temperature variation is of the order of $150 \mathrm{~K}$. The sharp drop in temperature between $60-\mathrm{mm}$ and $70-\mathrm{mm}$ is due to proximity to the wall.

The average temperature of the exhaust obtained using the radial temperature profiles was used to estimate the heat loss from the system. The software, Refprop 9.0 [36], was used to calculate the enthalpy of the exhaust. The exhaust temperatures estimated from the adiabatic flame temperature calculations were used as a reference for the heat loss calculation. It was found to be in the range of 
20-27\% for both the equivalence ratios, as shown in Fig. 7. The decrease in the heat loss percentage with flow rate was due to the higher fuel thermal input associated with the increase in flow rate.

\subsubsection{Measurements of Species Concentration}

Figures 8 and 9 represent of the experimentally obtained product species variation with flow rates for equivalence ratios of 4 and 5, respectively. It is interesting to note that there is no significant change in the species concentrations over the range of flow rates studied. The minor variation observed with respect to the flow rate could also be due to variation in the initial composition of syngas (up to $2 \%$ ) provided by the supplier. On the other hand, it is observed that the equivalence ratio has a significant influence on the product composition, indicating varying extent of consumption of the reactants. The species such as $\mathrm{H}_{2}$ and $\mathrm{CH}_{4}$ were consumed to a greater extent at $\Phi=4$ as compared to that at $\Phi=5$. The results also suggested that there was a net production of $\mathrm{CO}$ and $\mathrm{CO}_{2}$ and consumption of $\mathrm{CH}_{4}$ and $\mathrm{H}_{2}$. The production of $\mathrm{CO}$ is the result of the partial oxidation $\left(\mathrm{CH}_{4}+0.5 \mathrm{O}_{2} \rightarrow \mathrm{CO}+2 \mathrm{H}_{2}\right)$ and steam reforming $\left(\mathrm{CH}_{4}+\mathrm{H}_{2} \mathrm{O} \rightarrow \mathrm{CO}+3 \mathrm{H}_{2}\right)$ reactions of methane. It is important to note that there is a decrease in $\mathrm{CH}_{4}$ in products as the flow increases from 300 to 400 SLPM and then an increase at 500SLPM. This is explained as follows. From Fig. 5, one can observe that the exit temperature increases as the flow rate increases from 300 SLPM to 400 SLPM and remains almost same at 500 SLPM. This is to be expected as the temperature would increase with increase in heat input. However, between 400 SLPM and 500 SLPM, the increased heat input may be balanced by the increased heat loss to the walls, thus causing the temperature to remain nearly the same. Now, the higher temperature for the 400 SLPM case as compared to the 300 SLPM case tends to promote the steam reforming reaction of methane, which is endothermic. Therefore, the methane concentration decreases as flow rate changes from 300 to 400 SLPM. For the 400 and 500 SLPM cases, although the temperatures are almost the same, the residence time decreases. Thus, the effect of residence time dominates, leading to again a higher methane concentration at 500 SLPM.

A detailed insight into species concentrations are obtained using numerical simulations which are presented in the following section. It is worth noting that the $\mathrm{NO}_{\mathrm{x}}$ emissions were below 1-ppm in the current work, as expected, since the temperatures are well below those required for NO production.

\section{Computational Modeling}

The experimental studies were complemented by detailed numerical simulations conducted on a single channel of the monolith. The primary motivation for conducting the numerical simulations was to understand the temperature distribution and species profiles within a single channel. The accurate determination of the temperature inside the reactor is critical to the prevention of local hot spots that can damage the monolith. The axial profiles of temperature and species can help in understanding the effect of the channel length on the heat release and chemical kinetics.

\subsection{Numerical model}

*Corresponding author, Email: ravikris@mecheng.iisc.ernet.in 
A single channel of the catalytic monolith was numerically simulated to understand the combustion phenomena inside the reactor. The computational domain closely approximates the channels near the axis of the monolith. As shown in Figs. 10 and 11, a two-dimensional axisymmetric domain was selected for the numerical simulation, while maintaining the same channel surface area and inlet Reynolds number. The domain was divided into 14 and 350 divisions in the radial and axial direction with necessary biasing near the walls. The porous washcoat and substrate wall were divided into 4 and 6 divisions in the radial direction, respectively. The computational results were verified to be gridindependent. The governing equations of continuity, momentum and energy were discretized and solved using FLUENT. The details of the model for porous washcoat can be found elsewhere [37]. The Laminar Finite Rate model and the surface-to-surface radiation model were used to model the reactions and radiation. Table 3 describes the parameters used for the numerical simulations.

\subsection{Chemical kinetics}

For heterogeneous chemistry, the mechanism proposed by Deutschmann et al. [38] for the catalytic partial oxidation of $\mathrm{C}_{2} \mathrm{H}_{6}$ was used. Only the $\mathrm{C}_{1}$ surface species have been considered in the present study [39]. The scheme was further augmented by an updated $\mathrm{H}_{2} / \mathrm{CO}$ heterogeneous scheme reported by Mantzaras et al. [32]. The HCOO pathway included in the scheme has been reported to significantly affect the $\mathrm{CO}$ consumption for rich catalytic combustion of $\mathrm{H}_{2} / \mathrm{CO}$ mixtures over platinum [32]. The final mechanism consisted of 43 surface reactions with 12 surface species. For gas-phase chemistry, the $\mathrm{C}_{2} / \mathrm{H} / \mathrm{O}$ mechanism of Warnatz et al. [35] (164 reversible reactions and 34 species) was used. The scheme has been reported to accurately predict the onset of homogeneous ignition in $\mathrm{CPO}$ of methane diluted with $\mathrm{CO}_{2}$ and $\mathrm{H}_{2} \mathrm{O}$ [40].

\subsection{Results \& Discussion}

\subsubsection{Comparison with experimental results}

The comparison of predictions with experimental data is shown in Table 4. The predictions showed reasonable agreement with the experimentally-obtained values of temperature and $\mathrm{CO}$ concentration. It must be mentioned that the temperature measured along the axis of the monolith $(\mathrm{r}=0 \mathrm{~mm})$ was used for comparison. The slight discrepancy in temperature comparison can be attributed to the effect of heat loss in the reactor that was not accounted for in the single channel simulations. This factor also has an effect on the predictions of species composition. The most significant deviation could be observed in the prediction of $\mathrm{CH}_{4}$ that could have influenced the $\mathrm{H}_{2}$ and $\mathrm{H}_{2} \mathrm{O}$ concentration. The twodimensional axisymmetric assumption and the kinetic scheme selected could be other possible sources of disagreement between the experimental and computational results. However, the computations can be used to predict the maximum temperature in the reactor as it closely approximates the channels near the axis of the monolith where the highest temperature is observed. This is the key parameter for safe operation of the monolith. The species profiles obtained along the length of the channel also help in optimizing the length of the monolith.

*Corresponding author, Email: ravikris@mecheng.iisc.ernet.in 


\subsubsection{Temperature variation along the channel length}

Figure 12 shows temperature profile along the axis of the channel for equivalence ratios of 4 and 5 at a flow rate of 400 SLPM. The temperature increased rapidly near the inlet and marked the initiation of reactions within the channel. The temperature for $\Phi=5$ was lower than that of $\Phi=4$. Peak temperatures of $1150 \mathrm{~K}$ and $1050 \mathrm{~K}$ were achieved that decreased to $1066 \mathrm{~K}$ and $990 \mathrm{~K}$ for equivalence ratios of 4 and 5, respectively. The temperature profiles are gradual and no local hot spots characterized by sudden temperature rise can be observed. This further suggests that the present reactor can be operated safely at $\Phi=4$ and 5 .

\subsubsection{Variation of species along the channel length}

Figure 13 shows species profiles along the channel length averaged over the cross-section. It is observed that $\mathrm{H}_{2}$ is oxidized at the beginning of the channel leading to a sharp decrease in its mass fraction. The $\mathrm{H}_{2} \mathrm{O}$ concentration profile shows a rapid increase reflecting the corresponding decrease in the $\mathrm{H}_{2}$ concentration profile. The $\mathrm{O}_{2}$ mass fraction goes to zero within the first $5-10 \mathrm{~mm}$ of the channel as it is completely consumed by $\mathrm{H}_{2}$. In the absence of $\mathrm{O}_{2}$, the subsequent reaction of steamreforming of methane along the channel length takes place, leading to the gradual production of $\mathrm{H}_{2}$ and $\mathrm{CO}$ and consumption of $\mathrm{CH}_{4}$. The methane reforming reaction is endothermic, which explains the observed decrease in the temperature along the channel length.

The initial gradients in the species concentrations can be better observed in Figure 14 that shows the two-dimensional contours for the first $20-\mathrm{mm}$ of the channel. The reactions are predominantly governed by the surface chemistry as gas-phase reaction rates are insignificant at these temperatures. The reactions start near the surface where the initial rise in temperature and oxidation of reactants is observed. After the initial reaction zone, no significant variation along the channel radius can be observed.

From the temperature and species profiles, it can be concluded that the length of the reactor selected $(150-\mathrm{mm})$ is sufficient for the flow rates considered in the present study. This can also be corroborated by the fact that $\mathrm{O}_{2}$ is consumed within the first $10-\mathrm{mm}$ of the channel. The length of the channel $(150-\mathrm{mm})$ is approximately 15 times greater than the length required for complete $\mathrm{O}_{2}$ consumption $(\sim 10 \mathrm{~mm})$. This observation is very significant as it implies that the current reactor can be operated at flow rates much higher than the values used in the present study. However, there may be other limitations in extending the operation to such high flow rates and needs further investigation. Notwithstanding these limitations, it is reasonable to assume that the current reactor can operate at a wider range of turn-down ratios as compared to the turn-down ratio of 1.67 (ratio of maximum to minimum flow rates) that has been investigated in the present study.

\section{CONCLUSIONS}


The present work describes the development and operation of a catalytic combustion system as a possible hybrid heating source for solar-thermal power generation. Syngas containing $20 \% \mathrm{CO}$, $20 \% \mathrm{H}_{2}, 2 \% \mathrm{CH}_{4}, 12 \% \mathrm{CO}_{2}$ and $46 \% \mathrm{~N}_{2}$ and a calorific value of around $5 \mathrm{MJ} / \mathrm{m}^{3}$ has been used as the fuel. This composition closely represents the fuel obtained from biomass gasification. Detailed experimental studies have been conducted to assess the performance of the system in terms of parameters relevant to solar-thermal applications. Experimental data of temperature and species concentration at the exit of the reactor have been reported for a maximum fuel thermal input of $34 \mathrm{~kW}$ and a turn-down ratio of 1.67. The equivalence ratio and the flow rate are the primary parameters that have been varied. From temperature considerations, it was determined that the equivalence ratios of 4 and 5 were suitable for solar-thermal applications. The system also exhibited quick startup that is crucial in accommodating the fluctuations in solar power generation. A light-off time of around 60 seconds and a steady-state time of around 200 seconds were determined from the transient temperature profiles. The heat loss percentage from the reactor decreased with an increase in the flow rate and was found to be of the order of $20-27 \%$.

The experimental results have also been complemented with detailed two-dimensional numerical simulations for an improved understanding of the heat release and chemical kinetics in the catalytic combustor. The simulations confirmed the fact that no hotspots developed within the reactor inspite of the large $\mathrm{H}_{2}$ content in the fuel. More importantly, the simulations are able to predict the temperature rise across the combustor with reasonable accuracy (within 40-70 K). The species profiles along the monolith length show that the primary reaction zone is limited to within $10-\mathrm{mm}$ from the inlet. This insight from the simulations also suggests that the current combustor can sustain higher flow rates and operate over a much higher turn-down ratio ( 15). Stable operation, quick startup, and high turn-down ratio confirm the suitability of the current combustion system to be an important component of a hybrid heating source for solar-thermal power generation.

\section{Acknowledgement}

This paper is based upon work supported in part by the National Centre for Combustion Research \& Development (NCCRD) funded by the Science \& Engineering Research Board (SERB) of Government of India, and the US-India Partnership to Advance Clean Energy-Research (PACE-R) for the Solar Energy Research Institute for India and the United States (SERIIUS), funded jointly by the U.S. Department of Energy (Office of Science, Office of Basic Energy Sciences, and Energy Efficiency and Renewable Energy, Solar Energy Technology Program, under Subcontract DE-AC3608GO28308 to the National Renewable Energy Laboratory, Golden, Colorado) and the Government of India, through the Department of Science and Technology under Subcontract IUSSTF/JCERDCSERIIUS/2012 dated 22nd Nov. 2012.

\section{References}

*Corresponding author, Email: ravikris@mecheng.iisc.ernet.in 
[1] M.K. Deshmukh, S.S. Deshmukh, Modeling of hybrid renewable energy systems, Renew. Sustain. Energy Rev. 12 (2008) 235-249. doi:10.1016/j.rser.2006.07.011.

[2] S. Bentouba, M. Bourouis, Feasibility study of a wind-photovoltaic hybrid power generation system for a remote area in the extreme south of Algeria, Appl. Therm. Eng. (2015). doi:10.1016/j.applthermaleng.2015.12.014.

[3] Y. Shin, W.Y. Koo, T.H. Kim, S. Jung, H. Kim, Capacity design and operation planning of a hybrid PV-wind-battery-diesel power generation system in the case of Deokjeok Island. Appl. Therm. Eng. 89 (2015), 514-525. doi:10.1016/j.applthermaleng.2015.06.043

[4] J.P. Reichling, F.A. Kulacki, Utility scale hybrid wind-solar thermal electrical generation: A case study for Minnesota, Energy. 33 (2008) 626-638. doi:10.1016/j.energy.2007.11.001.

[5] G. Bekele, G. Tadesse, Feasibility study of small Hydro/PV/Wind hybrid system for off-grid rural electrification in Ethiopia, Appl. Energy. 97 (2012) 5-15. doi:10.1016/j.apenergy.2011.11.059.

[6] S. Kumaravel, S. Ashok, An optimal stand-alone biomass/solar-PV/pico-hydel hybrid energy system for remote rural area electrification of isolated village in Western-Ghats region of India. International Journal of Green $\quad$ Energy, 9(5) (2012), 398-408. doi:10.1080/15435075.2011.621487

[7] J.H. Peterseim, A. Herr, S. Miller, S. White, D.A. O'Connell, Concentrating solar power/alternative fuel hybrid plants: Annual electricity potential and ideal areas in Australia, Energy. 68 (2014) 698-711. doi:10.1016/j.energy.2014.02.068.

[8] J.D. Nixon, P.K. Dey, P.A. Davies, The feasibility of hybrid solar-biomass power plants in India, Energy. 46 (2012) 541-554. doi:10.1016/j.energy.2012.07.058.

[9] R. Soria, J. Portugal-Pereira, A. Szklo, R. Milani, R. Schaeffer, Hybrid concentrated solar power (CSP)-biomass plants in a semiarid region: A strategy for CSP deployment in Brazil, Energy Policy. 86 (2015) 57-72. doi:10.1016/j.enpol.2015.06.028.

[10] A. V Bridgwater, A.J. Toft, J.G. Brammer, A techno-economic comparison of power production by biomass fast pyrolysis with gasification and combustion, Renew. Sustain. Energy Rev. A.V. Bridg. Al. / Renew. Sustain. Energy Rev. 6 (2002) 181-248. doi:10.1016/S13640321(01)00010-7.

[11] K.R. Craig, M.K. Mann, Cost and performance analysis of biomass-based integrated gasification combined-cycle (BIGCC) power systems. Golden, CO: National Renewable Energy Laboratory (1996).

[12] W. Alonso-Pippo, C.A. Luengo, J. Koehlinger, P. Garzone, G. Cornacchia, Sugarcane energy use: The Cuban case, Energy Policy. 36 (2008) 2163-2181. doi:10.1016/j.enpol.2008.02.025.

[13] A. Evans, V. Strezov, T.J. Evans, Sustainability considerations for electricity generation from biomass, Renew. Sustain. Energy Rev. 14 (2010) 1419-1427. doi:10.1016/j.rser.2010.01.010.

[14] R.M. Sáez, P. Linares, J. Leal, Assessment of the externalities of biomass energy, and a comparison of its full costs with coal, Biomass and Bioenergy. 14 (1998) 469-478. doi:10.1016/S0961-9534(98)00016-6.

*Corresponding author, Email: ravikris@ mecheng.iisc.ernet.in 
[15] D. Styles, M.B. Jones, Energy crops in Ireland: Quantifying the potential life-cycle greenhouse gas reductions of energy-crop electricity, Biomass and Bioenergy. 31 (2007) 759-772. doi:10.1016/j.biombioe.2007.05.003.

[16] S. Dasappa, D.N. Subbukrishna, K.C. Suresh, P.J. Paul, G.S. Prabhu, Operational experience on a grid connected 100kWe biomass gasification power plant in Karnataka, India, Energy Sustain. Dev. 15 (2011) 231-239. doi:10.1016/j.esd.2011.03.004.

[17] M. Liu, N.H. Steven Tay, S. Bell, M. Belusko, R. Jacob, G. Will, W. Saman, F. Bruno, Review on concentrating solar power plants and new developments in high temperature thermal energy storage technologies, Renew. Sustain. Energy Rev. 53 (2016) 1411-1432. doi:10.1016/j.rser.2015.09.026.

[18] A. Kribus, P. Doron, R. Rubin, J. Karni, R. Reuven, S. Duchan, E. Taragan, A multistage solar receiver: the route to high temperature, Sol. Energy. 67 (2000) 3-11. doi:10.1016/S01406701(01)80433-1.

[19] T. Lieuwen, V. Yang, R. Yetter, Synthesis gas combustion: fundamentals and applications, 2009, CRC Press.

[20] J. Mantzaras, Catalytic Combustion of Syngas, Combust. Sci. Technol. 180 (2008) 11371168. doi:10.1080/00102200801963342.

[21] S. Pramanik, R. V. Ravikrishna, A Novel Syngas-fired Hybrid Heating Source for SolarThermal Applications: Energy and Exergy Analysis, Appl. Therm. Eng. (2016). (Accepted, Manuscript number: ATE-2016-11952)

[22] S. Etemad, L. L. Smith, K. Burns, System study of rich catalytic/lean burn (RCL) catalytic combustion for natural gas and coal-derived syngas combustion turbines. DOE final report DE-FG2602NT41521, DOE, Precision Combustion (2004).

[23] L.L. Smith, H. Karim, M.J. Castaldi, S. Etemad, W.C. Pfefferle, Rich-Catalytic Lean-burn combustion for fuel-flexible operation with ultra low emissions, Catal. Today. 117 (2006) 438-446. doi:10.1016/j.cattod.2006.06.021.

[24] M. Schultze, J. Mantzaras, R. Bombach, K. Boulouchos, An experimental and numerical investigation of the hetero-/homogeneous combustion of fuel-rich hydrogen/air mixtures over platinum, Proc. Combust. Inst. 34 (2013) 2269-2277. doi:10.1016/j.proci.2012.05.029.

[25] M. Schultze, J. Mantzaras, Hetero-/homogeneous combustion of hydrogen/air mixtures over platinum: Fuel-lean versus fuel-rich combustion modes, Int. J. Hydrogen Energy. 38 (2013) 1065410670. doi:10.1016/j.ijhydene.2013.06.069.

[26] M. Maestri, A. Beretta, T. Faravelli, G. Groppi, E. Tronconi, D.G. Vlachos, Two-dimensional detailed modeling of fuel-rich H2 combustion over Rh / A12 O3 catalyst, Chem. Eng. Sci. 63 (2008) 2657-2669. doi:10.1016/j.ces.2008.02.024.

[27] B.C. Enger, R. Lodeng, A. Holmen, A review of catalytic partial oxidation of methane to synthesis gas with emphasis on reaction mechanisms over transition metal catalysts, Appl. Catal. aGeneral. 346 (2008) 1-27. doi:10.1016/j.apcata.2008.05.018.

*Corresponding author, Email: ravikris@mecheng.iisc.ernet.in 

on the transient behavior of partial oxidation of methane in a catalytic, monolith, Chem. Eng. Sci. 58 (2003) 633-642. ISI:000181575600014.

[29] R. Horn, K.A. Williams, N.J. Degenstein, A. Bitsch-Larsen, D. Dalle Nogare, S.A. Tupy, L.D. Schmidt, Methane catalytic partial oxidation on autothermal $\mathrm{Rh}$ and $\mathrm{Pt}$ foam catalysts: Oxidation and reforming zones, transport effects, and approach to thermodynamic equilibrium, J. Catal. 249 (2007) 380-393. doi:10.1016/j.jcat.2007.05.011.

[30] J.A. Federici, D.G. Vlachos, Experimental studies on syngas catalytic combustion on Pt/Al2O3 in a microreactor, Combust. Flame. 158 (2011) 2540-2543. doi:10.1016/j.combustflame.2011.05.003.

[31] X. Zheng, J. Mantzaras, R. Bombach, Homogeneous combustion of fuel-lean syngas mixtures over platinum at elevated pressures and preheats, Combust. Flame. 160 (2013) 155-169. doi:10.1016/j.combustflame.2012.09.001.

[32] M. Schultze, J. Mantzaras, F. Grygier, R. Bombach, Hetero-/homogeneous combustion of syngas mixtures over platinum at fuel-rich stoichiometries and pressures up to 14 bar, Proc. Combust. Inst. 35 (2015) 2223-2231. doi:10.1016/j.proci.2014.05.018.

[33] P. Garg, P. Kumar, K. Srinivasan, Supercritical carbon dioxide Brayton cycle for concentrated solar power, J. Supercrit. Fluids. 76 (2013) 54-60. doi:10.1016/j.supflu.2013.01.010.

[34] A.L. Brundage, S.P. Kearney, A.B. Donaldson, V.F. Nicolette, W. Gill, A Joint Computational and Experimental Study to Evaluate Inconel-Sheathed Thermocouple Performance in Flames. Sandia National Laboratories (2005).

[35] J. Warnatz, U. Maas, R.W. Dibble, Combustion (Vol. 3). Berlin: Springer (2001).

[36] E.W. Lemmon, M.L. Huber, M.O. McLinden, Refprop 9.0, NIST standard reference database 23, Version 9.02010.

[37] N. Mladenov, J. Koop, S. Tischer, O. Deutschmann, Modeling of transport and chemistry in channel flows of automotive catalytic converters, Chem. Eng. Sci. 65 (2010) 812-826. doi:10.1016/j.ces.2009.09.034.

[38] D.K. Zerkle, M.D. Allendorf, M. Wolf, O. Deutschmann, Understanding homogeneous and heterogeneous contributions to the platinum-catalyzed partial oxidation of ethane in a short-contacttime reactor, J. Catal. 196 (2000) 18-39. doi:10.1006/jcat.2000.3009.

[39] R. Quiceno, J. Pérez-Ramírez, J. Warnatz, O. Deutschmann, Modeling the high-temperature catalytic partial oxidation of methane over platinum gauze: Detailed gas-phase and surface chemistries coupled with 3D flow field simulations, Appl. Catal. A Gen. 303 (2006) 166-176. doi:10.1016/j.apcata.2006.01.041.

[40] A. Schneider, J. Mantzaras, R. Bombach, S. Schenker, N. Tylli, P. Jansohn, (2007). Laser induced fluorescence of formaldehyde and Raman measurements of major species during partial catalytic oxidation of methane with large $\mathrm{H}_{2} \mathrm{O}$ and $\mathrm{CO}_{2}$ dilution at pressures up to 10bar. Proc. Combust. Inst. 33 (2007) 1973-1981. doi:10.1016/j.proci.2006.08.076.

*Corresponding author, Email: ravikris@ mecheng.iisc.ernet.in 


\section{List of Figures}

1. Figure 1: Schematic diagram of the experimental setup. Thermocouples were also placed at various radial locations (at 10-mm intervals) at the outlet of the monolith. Abbreviations: MFC - mass flow controller; TC - thermocouple; $\mathrm{T}$ - temperature

2. Figure 2: Variation of adiabatic flame temperature as a function of equivalence ratio $(\Phi)$ for an inlet temperature of $503 \mathrm{~K}$.

3. Figure 3: Transient temperature profiles at the inlet and outlet of the catalytic reactor obtained at 500 SLPM (top) and 300 SLPM (below) for both equivalence ratios.

4. Figure 4: Variation of light-off and transient time (seconds) with flow rate (SLPM) for two different equivalence ratios.

5. Figure 5: Variation of exit temperatures with flow rate for equivalence ratios of 4 and 5.

6. Figure 6: Radial variation of temperature at the combustor outlet for equivalence ratios of 4 and 5, and flow rate of 300 SLPM.

7. Figure 7: Variation of the percentage of heat loss with flow rate at equivalence ratios of 4 and 5.

8. Figure 8: Variation of outlet species mass fractions with flow rate for an equivalence ratio of 4.

9. Figure 9: Variation of outlet species mass fractions with flow rate for an equivalence ratio of 5.

10. Figure 10: 2-D axisymmetric domain that was considered for simulation. $t_{w}$ refers to the wall thickness while $t_{p}$ refers to the thickness of the porous layer.

11. Figure 11: Actual grid shown up to $10 \mathrm{~mm}$ of the channel.

12. Figure 12: Temperature along the axis of the monolith channel for equivalence ratios of 4 and 5 for a flow rate of 400 SLPM, obtained via numerical simulations.

13. Figure 13. Species mass fraction along the channel for 400 SLPM and equivalence ratio 5, obtained via numerical simulations. The values are averaged over the cross-section at every point along the length of the channel.

14. Figure 14: Two-dimensional contours of species and temperature up to $20 \mathrm{~mm}$ of the channel for 400 SLPM and equivalence ratio 5. 


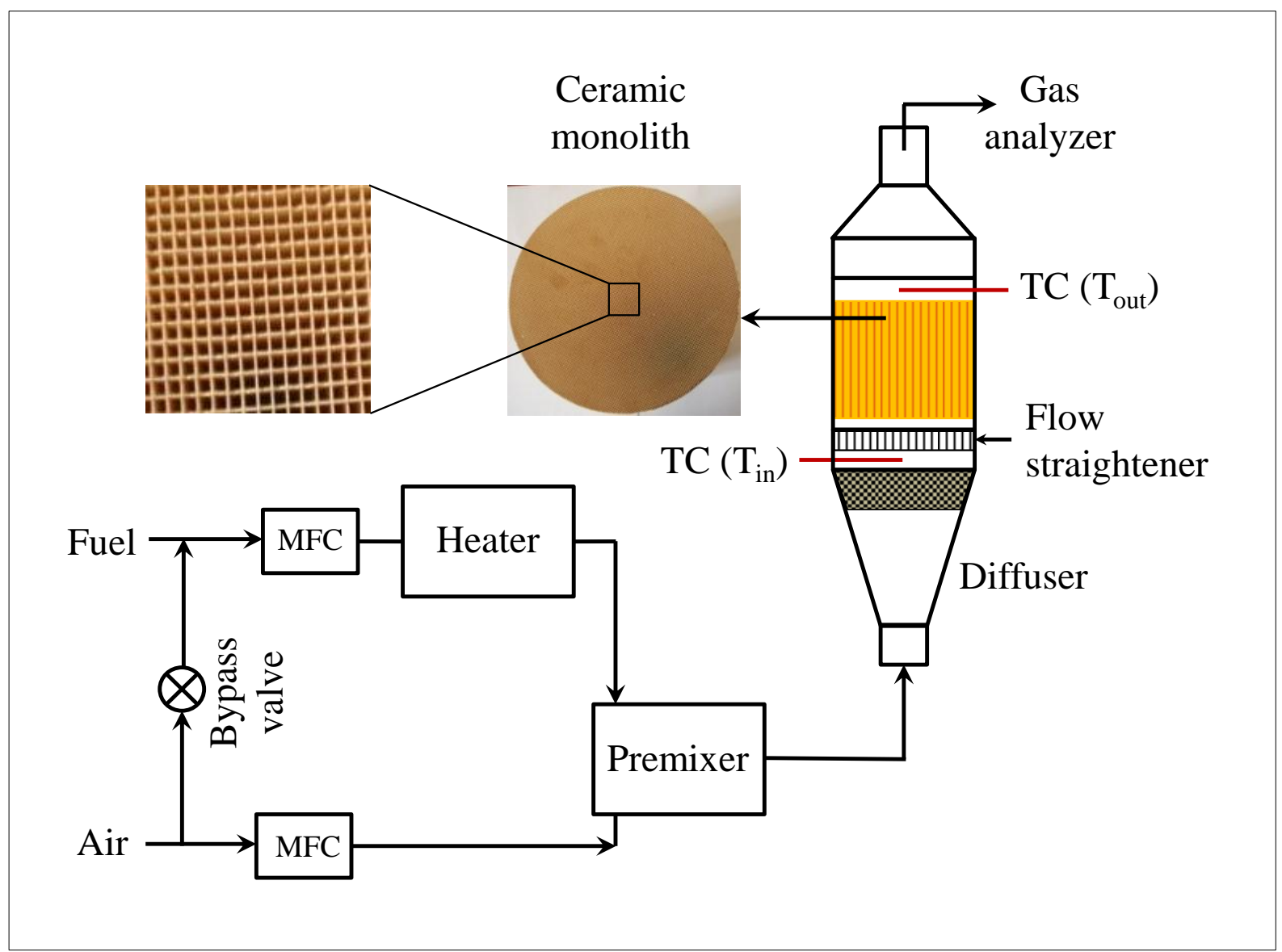

Figure 1: Schematic diagram of the experimental setup. Thermocouples were also placed at various radial locations (at 10-mm intervals) at the outlet of the monolith. Abbreviations: MFC - mass flow controller; $\mathrm{TC}$ - thermocouple; $\mathrm{T}$ - temperature 


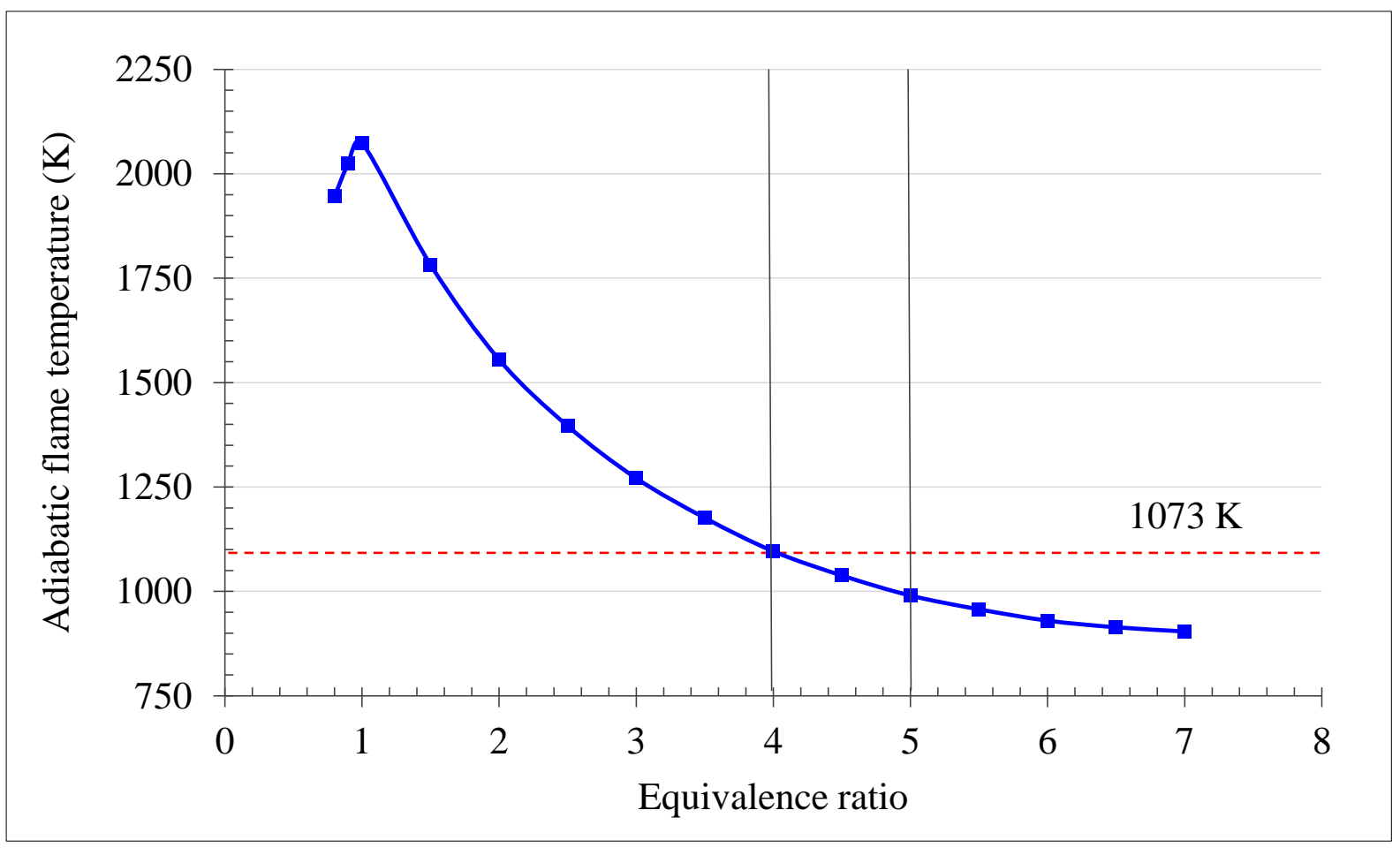

Figure 2: Variation of adiabatic flame temperature as a function of equivalence ratio $(\Phi)$ for an inlet temperature of $503 \mathrm{~K}$. 

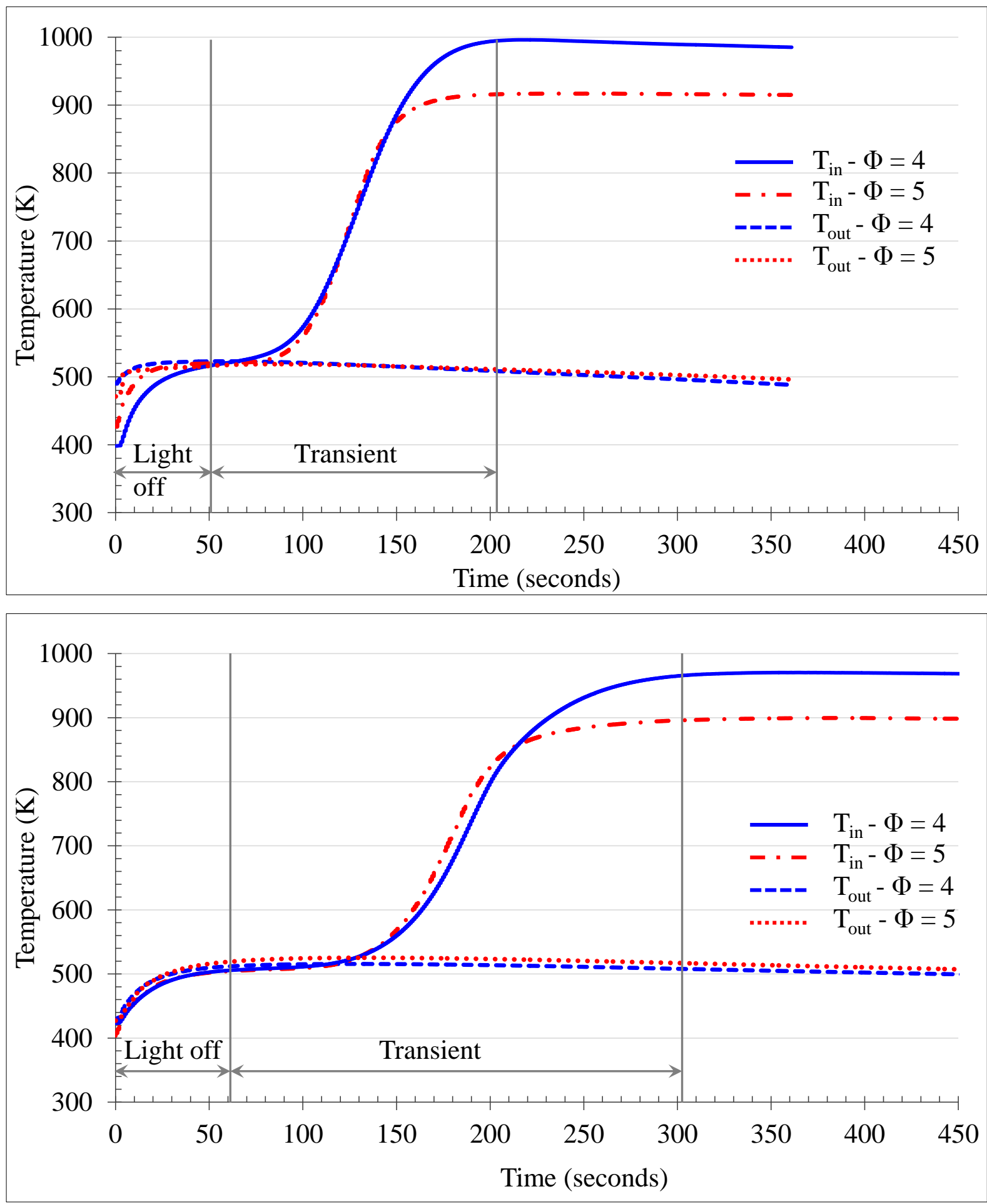

Figure 3: Transient temperature profiles at the inlet and outlet of the catalytic reactor obtained at 500 SLPM (top) and 300 SLPM (below) for both equivalence ratios. 


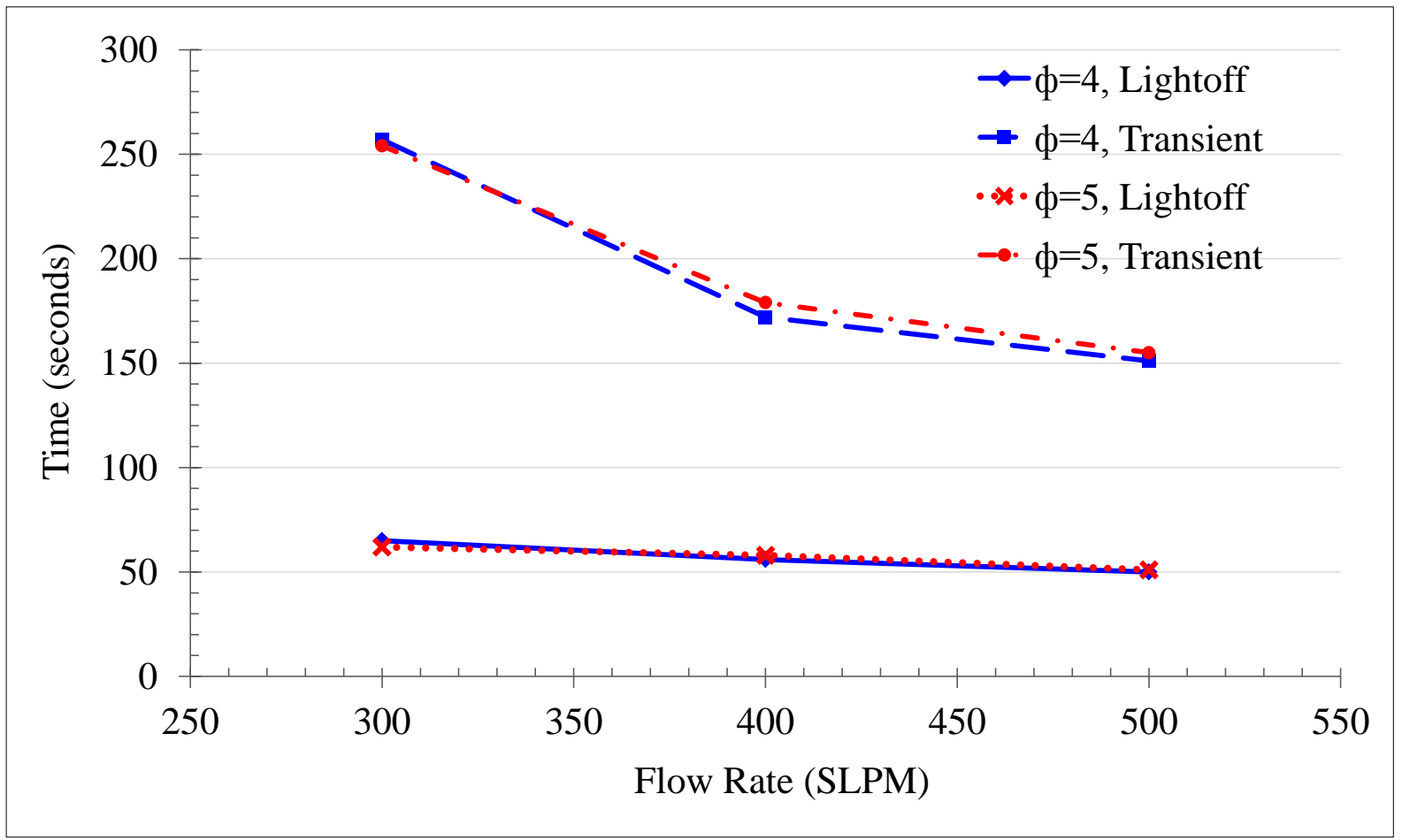

Figure 4: Variation of light-off and transient time (seconds) with flow rate (SLPM) for two different equivalence ratios. 


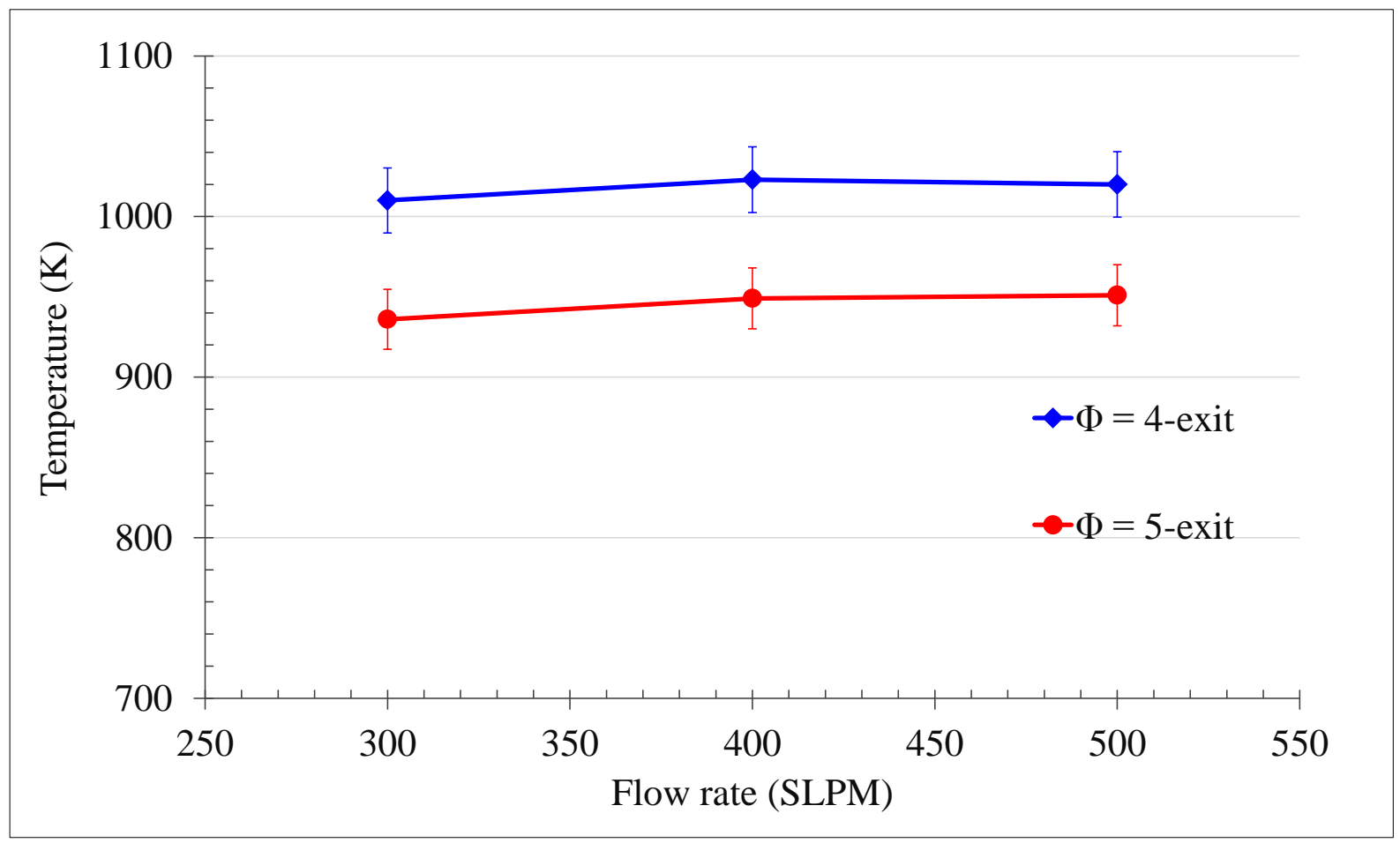

Figure 5: Variation of exit temperatures with flow rate for equivalence ratios of 4 and 5. 


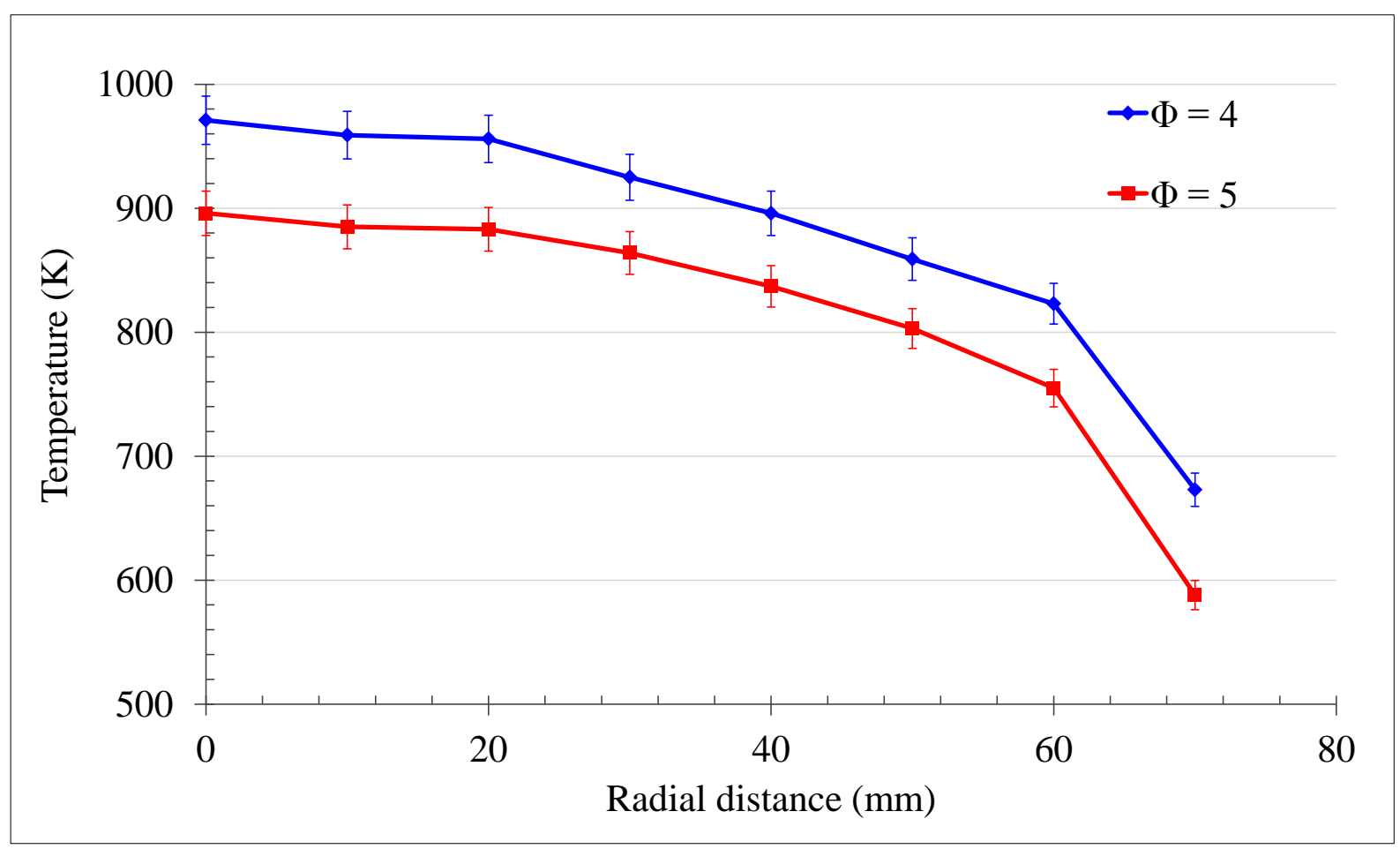

Figure 6: Radial variation of temperature at the combustor outlet for equivalence ratios of 4 and 5, and flow rate of 300 SLPM. 


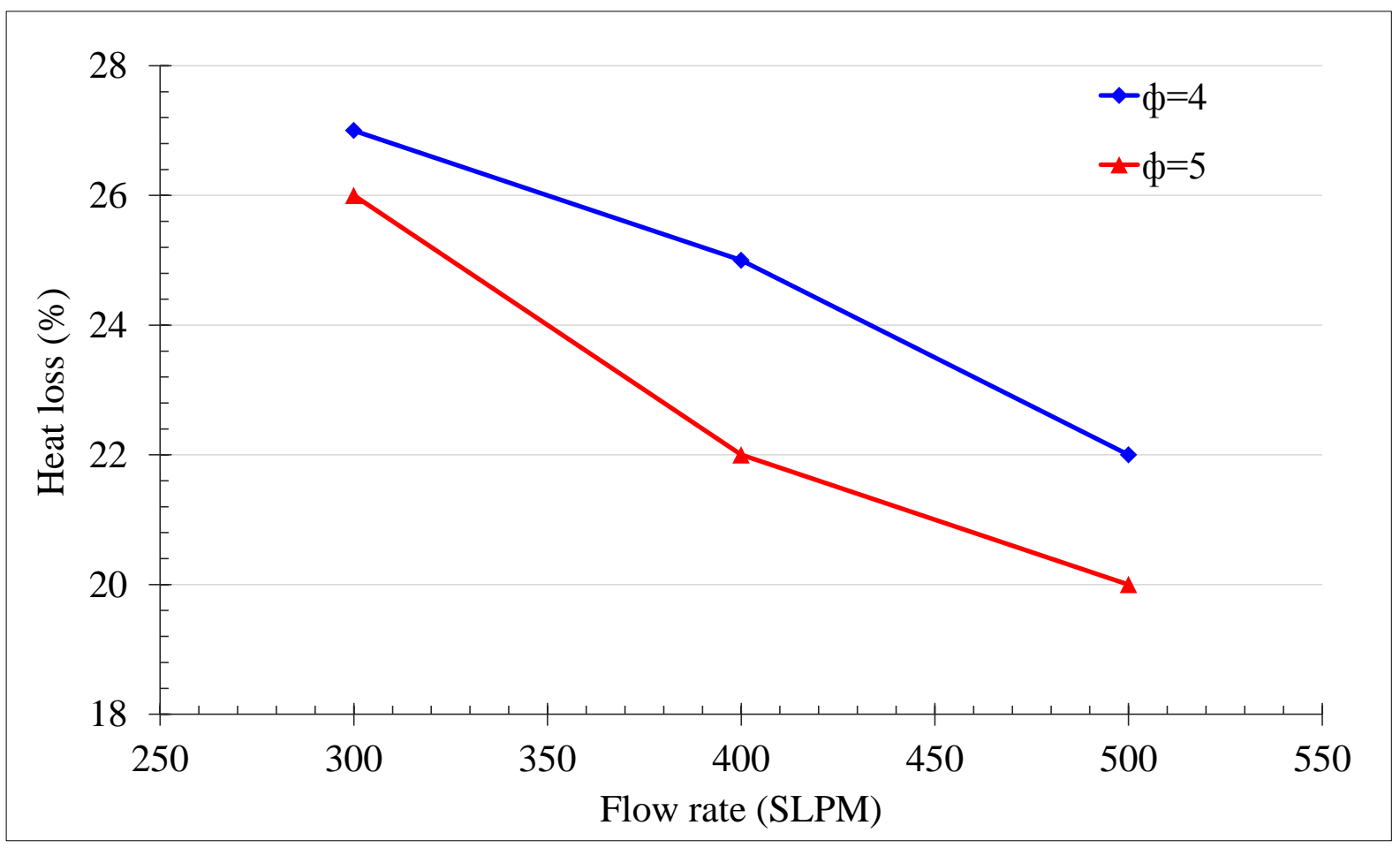

Figure 7: Variation of the percentage of heat loss with flow rate at equivalence ratios of 4 and 5. 


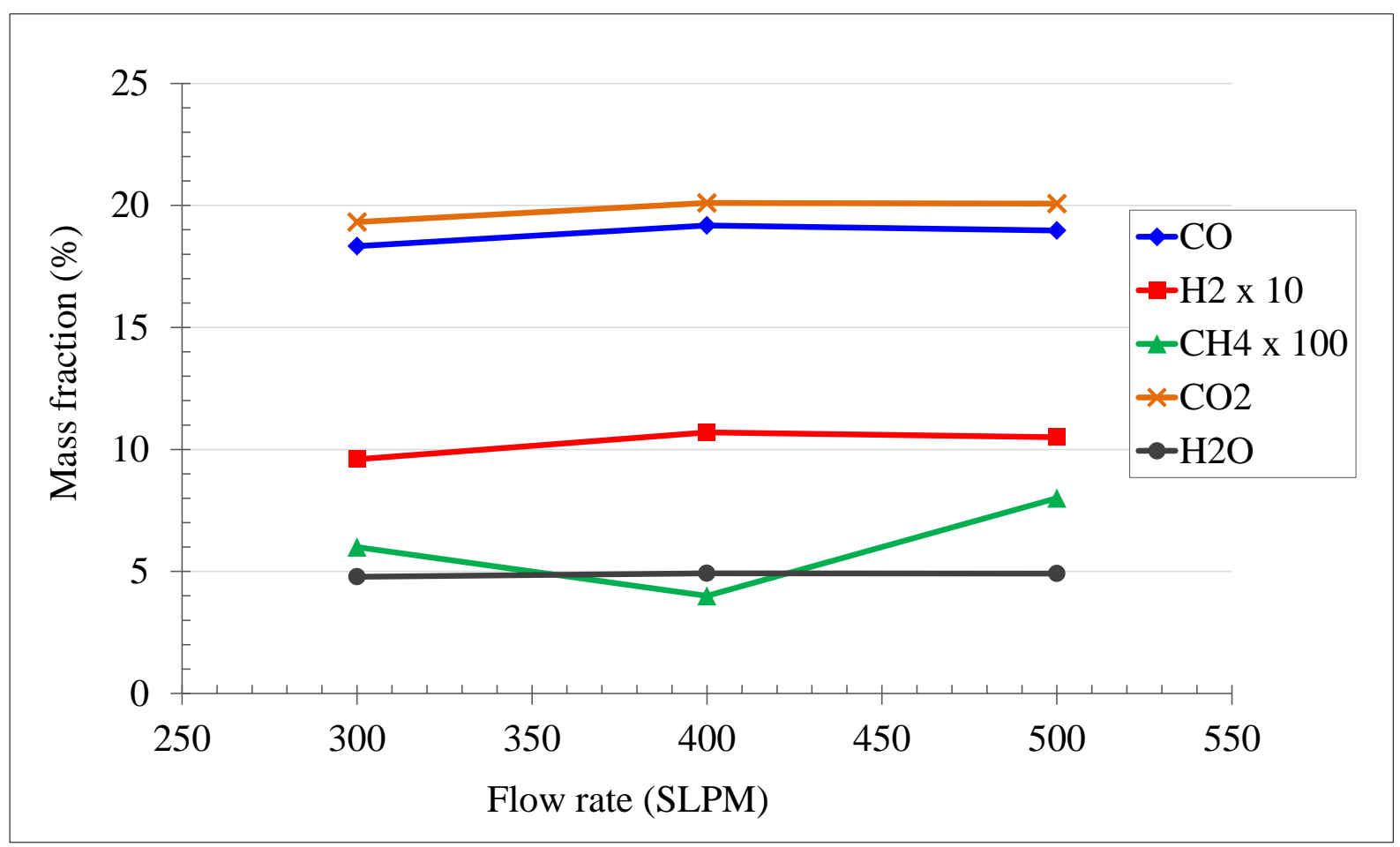

Figure 8: Variation of outlet species mass fractions with flow rate for an equivalence ratio of 4. 


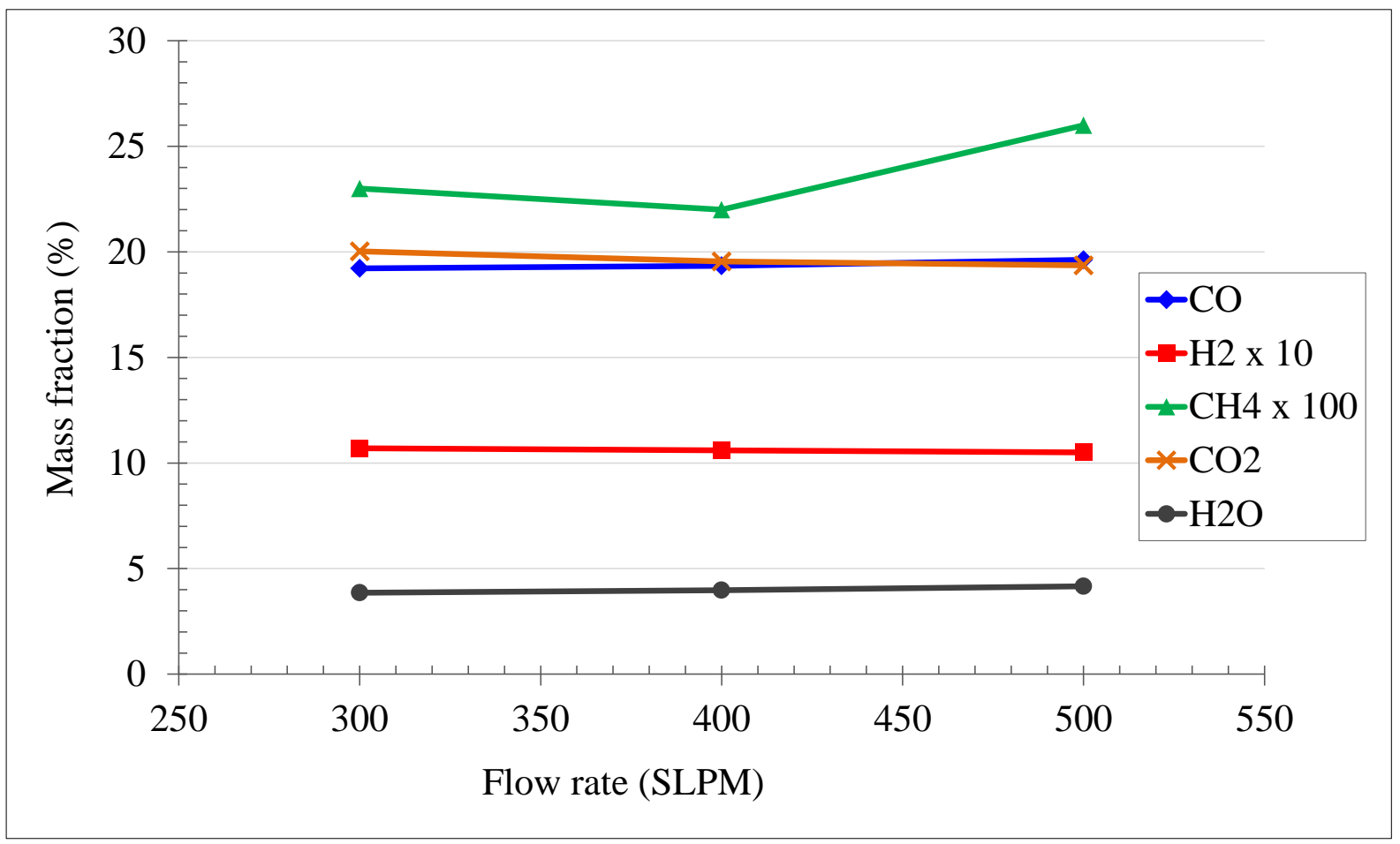

Figure 9: Variation of outlet species mass fractions with flow rate for an equivalence ratio of 5. 


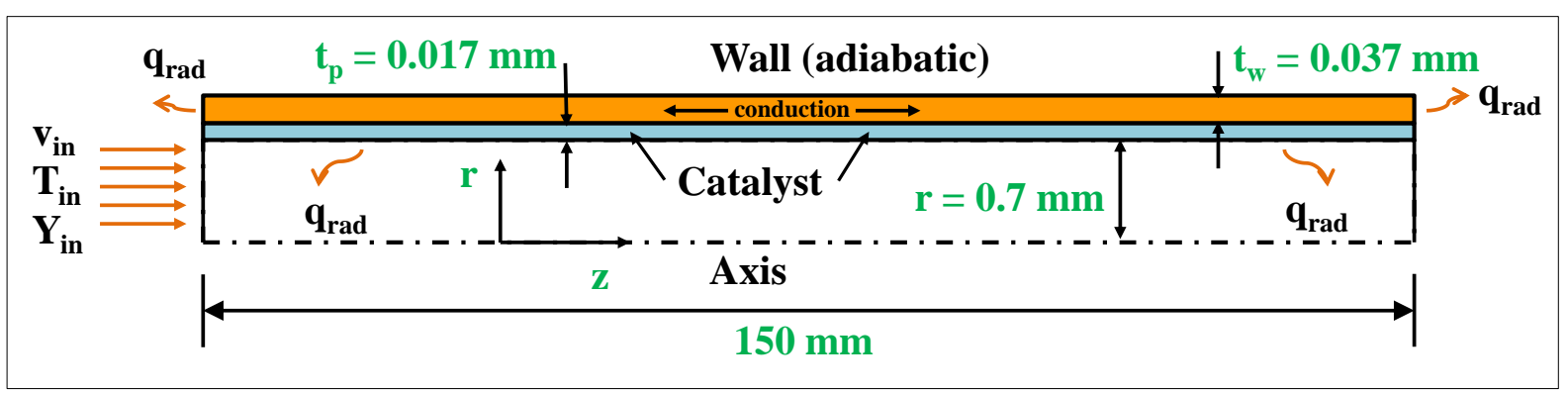

Figure 10: 2-D axisymmetric domain that was considered for simulation. $\mathrm{t}_{\mathrm{w}}$ refers to the wall thickness while $t_{p}$ refers to the thickness of the porous layer. 


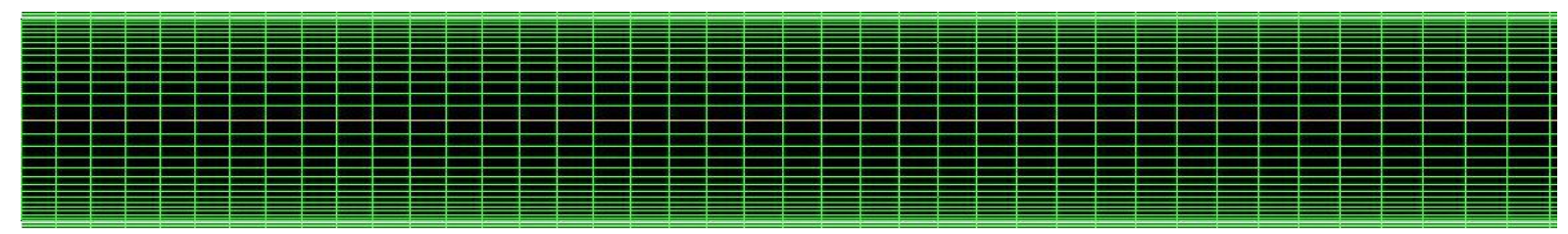

Figure 11: Actual grid shown up to $10 \mathrm{~mm}$ of the channel. 


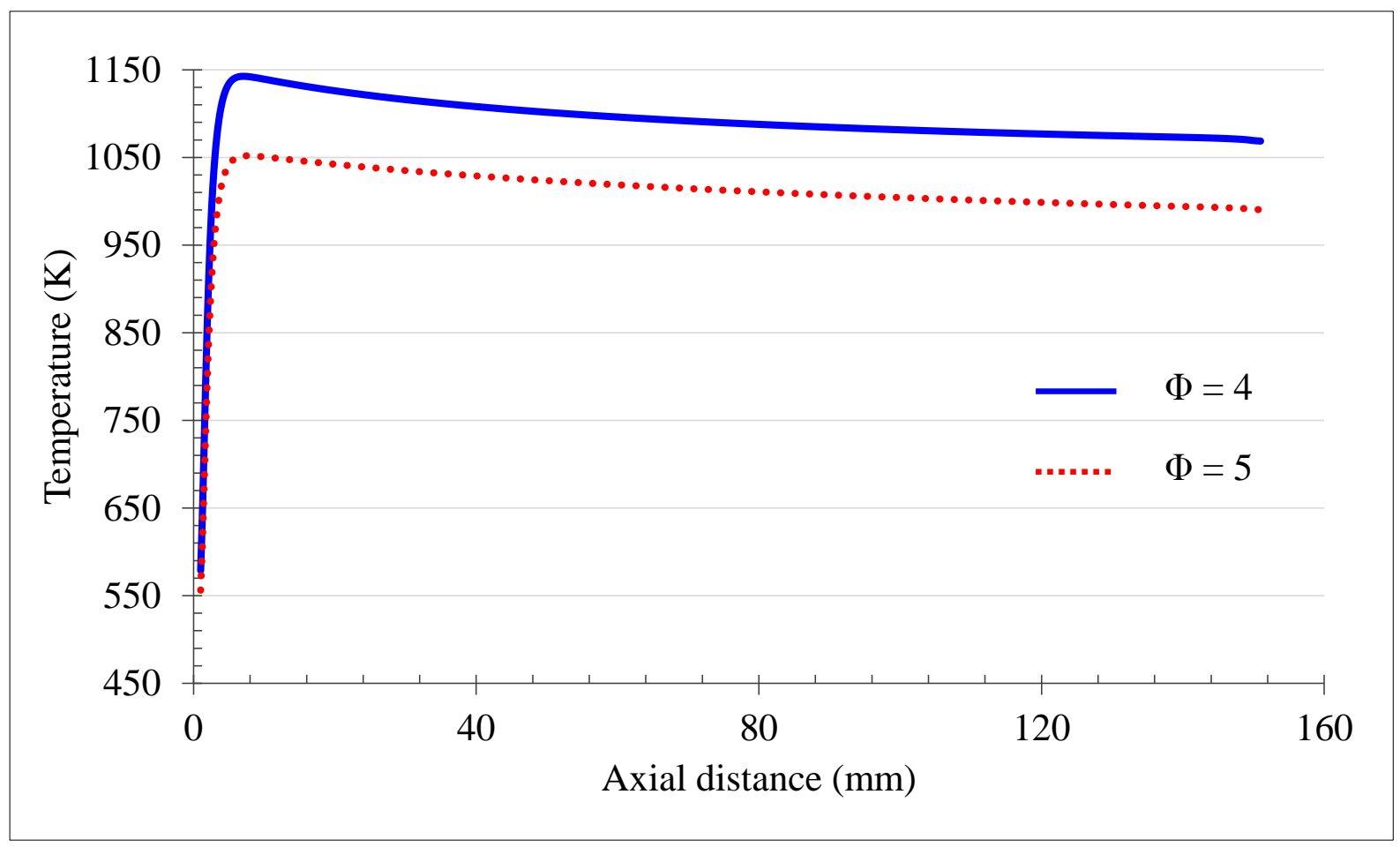

Figure 12: Temperature along the axis of the monolith channel for equivalence ratios of 4 and 5 for a flow rate of 400 SLPM, obtained via numerical simulations. 


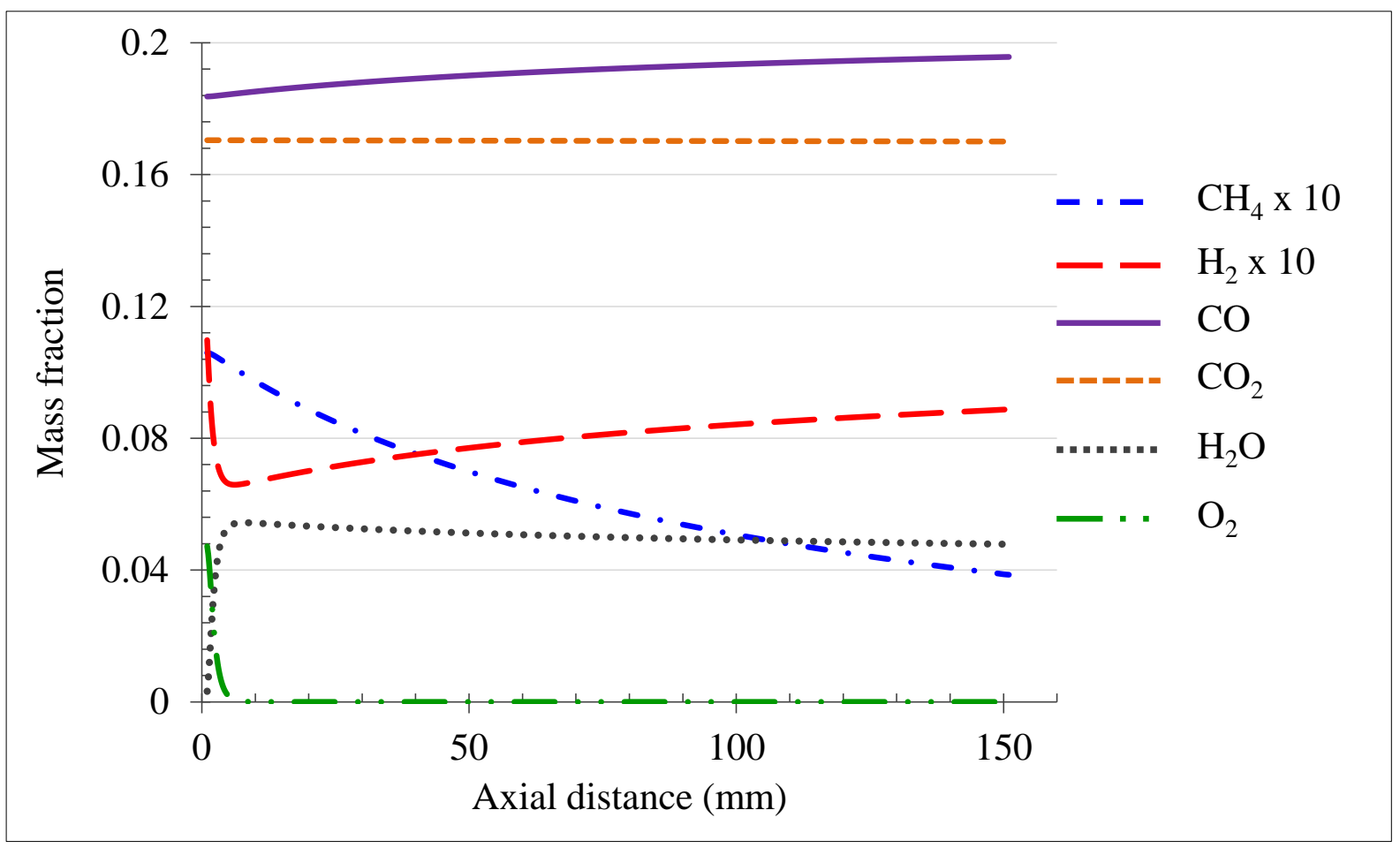

Figure 13: Species mass fraction along the channel for 400 SLPM and equivalence ratio 5, obtained via numerical simulations. The values are averaged over the cross-section at every point along the length of the channel. 


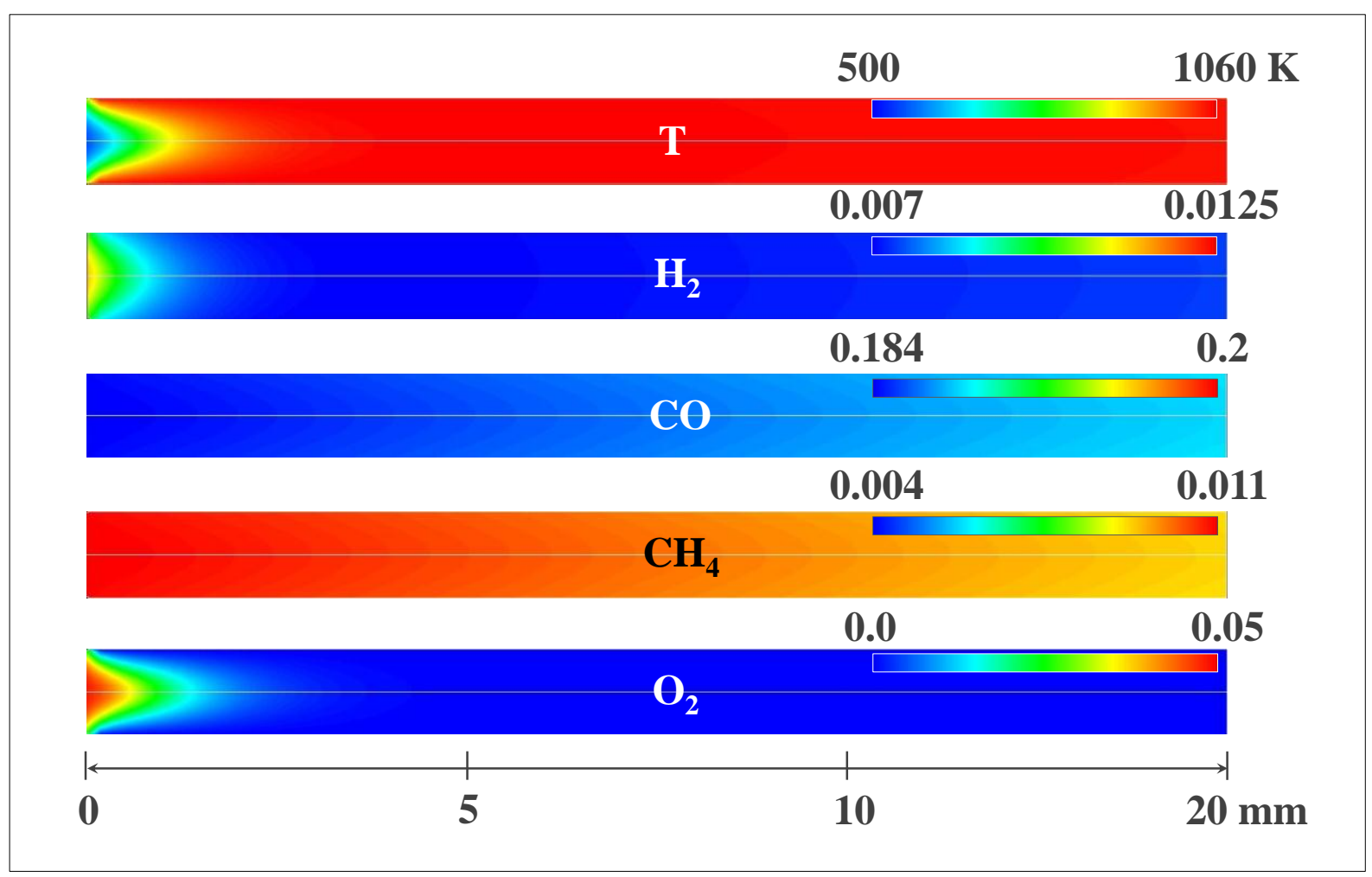

Figure 14: Two-dimensional contours of species and temperature up to $20 \mathrm{~mm}$ of the channel for 400 SLPM and equivalence ratio 5. 


\section{List of Tables}

1. Table 1: Specifications of the catalytic monolith.

2. Table 2: Experimental conditions

3. Table 3: Parameters used for the numerical simulations

4. Table 4: Comparison between experimental and computational results

Table 1: Specifications of the catalytic monolith.

*Corresponding author, Email: ravikris@mecheng.iisc.ernet.in 


\begin{tabular}{|l|l|}
\hline Property & Specification \\
\hline Material & Cordierite \\
\hline Chemical composition & $\mathrm{Al}_{2} \mathrm{O}_{3}: 35.2 \pm 1.5 \%, \mathrm{SiO}_{2}: 50.9 \pm 1.5 \%, \mathrm{MgO}: 13.9 \pm 1.5 \%$ \\
\hline Porosity of washcoat & $45 \%$ \\
\hline Catalyst & Platinum \\
\hline Catalyst loading & $10 \mathrm{gm} / \mathrm{ft}^{3}$ \\
\hline $\begin{array}{l}\text { Maximum allowable } \\
\text { temperature }\end{array}$ & $\begin{array}{l}1200^{\circ} \mathrm{C} \text { for intermittent operation, } 800^{\circ} \mathrm{C} \text { for continuous } \\
\text { operation }\end{array}$ \\
\hline Average pore diameter & $7-10 \mu \mathrm{m}$ \\
\hline Channel hydraulic diameter & $1.1 \mathrm{~mm}$ \\
\hline Wall thickness & $0.15 \mathrm{~mm}$ \\
\hline Outer dimensions & Diameter $=150 \mathrm{~mm}$, length $=150 \mathrm{~mm}$ \\
\hline Channel Density & 400 channels per square inch \\
\hline Washcoat Thickness & $17 \mu \mathrm{m}$ \\
\hline
\end{tabular}


Table 2: Experimental conditions

\begin{tabular}{|c|c|c|c|c|c|}
\hline$\Phi$ & mass composition & $\begin{array}{l}\text { Total flow } \\
\text { (SLPM) }\end{array}$ & $\begin{array}{c}\text { Air } \\
(\mathrm{SLPM})\end{array}$ & $\begin{array}{c}\text { Fuel } \\
\text { (SLPM) }\end{array}$ & $\begin{array}{l}\text { Fuel thermal } \\
\text { loading }(\mathrm{kW})\end{array}$ \\
\hline \multirow{3}{*}{4} & \multirow{3}{*}{$\begin{array}{c}17.13 \% \mathrm{CO}, 16.16 \% \mathrm{CO}_{2} \\
1.22 \% \mathrm{H}_{2}, 0.98 \% \mathrm{CH}_{4}, 5.86 \% \\
\mathrm{O}_{2}, 58.65 \% \mathrm{~N}_{2}\end{array}$} & 300 & 66.5 & 233.5 & 19.5 \\
\hline & & 400 & 88.7 & 311.3 & 25.9 \\
\hline & & 500 & 109.9 & 389.1 & 32.4 \\
\hline \multirow{3}{*}{5} & \multirow{3}{*}{$\begin{array}{c}18.04 \% \mathrm{CO}, 17.01 \% \mathrm{CO}_{2}, \\
1.29 \% \mathrm{H}_{2}, 1.03 \% \mathrm{CH}_{4}, 4.94 \% \\
\mathrm{O}_{2}, 57.70 \% \mathrm{~N}_{2}\end{array}$} & 300 & 55.7 & 244.3 & 20.4 \\
\hline & & 400 & 74.3 & 325.7 & 27.1 \\
\hline & & 500 & 92.8 & 407.2 & 33.9 \\
\hline
\end{tabular}


Table 3: Parameters used for the numerical simulations

\begin{tabular}{|c|c|}
\hline \multicolumn{2}{|l|}{ Channel dimensions } \\
\hline Diameter & $1.4 \mathrm{~mm}$ \\
\hline Length & $150 \mathrm{~mm}$ \\
\hline \multicolumn{2}{|l|}{ Ceramic substrate } \\
\hline Material & Cordierite \\
\hline Thickness & $0.037 \mathrm{~mm}$ \\
\hline Thermal conductivity & $3 \mathrm{~W} / \mathrm{m} . \mathrm{K}$ \\
\hline Density & $2600 \mathrm{~kg} / \mathrm{m}^{3}$ \\
\hline Specific heat & $1464 \mathrm{~J} / \mathrm{kg} . \mathrm{K}$ \\
\hline \multicolumn{2}{|l|}{ Washcoat } \\
\hline Washcoat thickness & $0.017 \mathrm{~mm}$ \\
\hline $\mathrm{F}_{\text {cat/geo }}($ washcoat factor $)$ & 7 \\
\hline Thermal conductivity & $25 \mathrm{~W} / \mathrm{m} . \mathrm{K}$ \\
\hline Density of the solid & $3690 \mathrm{~kg} / \mathrm{m}^{3}$ \\
\hline Specific heat & $880 \mathrm{~J} / \mathrm{kg} . \mathrm{K}$ \\
\hline \multicolumn{2}{|l|}{ Other parameters } \\
\hline Wall emissivity $(\varepsilon)$ & 0.6 \\
\hline
\end{tabular}


Table 4: Comparison between experimental and computational results

\begin{tabular}{|c|c|c|c|c|c|c|c|c|c|c|c|c|c|}
\hline & & \multicolumn{12}{|c|}{ Mass fraction of products $(\%)$} \\
\hline \multicolumn{2}{|c|}{ Cases } & \multicolumn{2}{|c|}{$\mathrm{CO}$} & \multicolumn{2}{|c|}{$\mathrm{CO}_{2}$} & \multicolumn{2}{|c|}{$\mathrm{CH}_{4}$} & \multicolumn{2}{|c|}{$\mathrm{H}_{2}$} & \multicolumn{2}{|c|}{$\mathrm{H}_{2} \mathrm{O}$} & \multicolumn{2}{|c|}{$\Delta \mathrm{T}(\mathrm{K})$} \\
\hline$\Phi$ & Flow rate & Exp. & CFD & Exp. & CFD & Exp. & CFD & Exp. & CFD & Exp. & CFD & Exp & CFD \\
\hline \multirow{3}{*}{4} & 300 & 18.33 & 18.6 & 19.32 & 15.8 & 0.06 & 0.09 & 0.96 & 0.86 & 4.78 & 5.6 & 498 & 546 \\
\hline & 400 & 19.18 & 19.2 & 20.10 & 16.42 & 0.04 & 0.146 & 1.07 & 0.86 & 4.92 & 5.68 & 516 & 559 \\
\hline & 500 & 18.97 & 19.17 & 20.07 & 16.43 & 0.08 & 0.16 & 1.05 & 0.854 & 4.91 & 5.68 & 516 & 592 \\
\hline \multirow{3}{*}{5} & 300 & 19.22 & 20.11 & 20.02 & 16.8 & 0.23 & 0.31 & 1.07 & 0.96 & 3.86 & 4.73 & 436 & 483 \\
\hline & 400 & 19.34 & 19.57 & 19.54 & 17 & 0.22 & 0.387 & 1.06 & 0.89 & 3.97 & 4.77 & 449 & 490 \\
\hline & 500 & 19.62 & 19.48 & 19.36 & 17 & 0.26 & 0.43 & 1.05 & 0.88 & 4.16 & 4.82 & 445 & 495 \\
\hline
\end{tabular}

